\title{
Involvement of Arp2/3 complex in the process of colorectal carcinogenesis
}

\author{
Toshiya Otsubo ${ }^{1,3}$, Keiichi Iwaya ${ }^{2}$, Yasuo Mukai ${ }^{1}$, Yuji Mizokami ${ }^{3}$, Hiromi Serizawa ${ }^{2}$, \\ Takeshi Matsuoka ${ }^{3}$ and Kiyoshi Mukai ${ }^{1}$ \\ ${ }^{1}$ Department of Pathology, Tokyo Medical University, Shinjuku-ku, Tokyo, Japan; ${ }^{2}$ Division of Surgical \\ Pathology, Tokyo Medical University Hospital, Shinjuku-ku, Tokyo, Japan and ${ }^{3}$ Fifth Department of Internal \\ Medicine, Tokyo Medical University, Inashiki, Ibaraki, Japan
}

\begin{abstract}
Increased motility is one of the characteristics of cancer cells, and actin polymerization and disassembly are essential for cellular motility. Since actin-related protein (Arp) 2/3 complex acts as a nucleus for actin polymerization, in this study, we immunohistochemically investigated the expression of Arp2 and Arp3 in 175 colorectal tumors in various stages of neoplastic progression. Arp2 and Arp3 showed identical expression patterns, and both were expressed in the stromal cells around neoplastic tubules or glands and in the tumor cells themselves. The frequency of expression of Arp2 and Arp3 (Arp2\&3) by the stromal cells increased with the atypia of the colorectal neoplasms, from $5.5 \%(3 / 55)$ in adenoma with mild or moderate atypia, to $11.8 \%$ $(2 / 17)$ in adenoma with severe atypia, 53.3\% (16/30) in intramucosal carcinoma, and $91.8 \%(67 / 73)$ in invasive carcinoma $(P<0.0001)$. The frequency of expression of Arp2\&3 in the tumor cells was similar and was $1.8 \%$ $(1 / 55)$ in adenoma with mild or moderate atypia, $23.5 \%(4 / 17)$ in adenoma with severe atypia, $23.5 \%(7 / 30)$ in intramucosal carcinoma, and 32.9\% (24/73) in invasive carcinoma. Expression of Arp2\&3 by the stromal cells was significantly correlated with nuclear accumulation of p53 in the tumor cells and stromal expression of CD10. These results suggest that formation of Arp2/3 complex by both neoplastic and stromal cells contributes to the increased motility of both cell types and thus provides suitable conditions for invasion.

Modern Pathology (2004) 17, 461-467, advance online publication, 27 February 2004; doi:10.1038/modpathol.3800062
\end{abstract}

Keywords: Arp2/3 complex; colorectal tumor; tumor-stromal interaction; stromal cell; invasion

Cell movement is mediated by the formation and disassembly of actin filaments and is indispensable to embryogenesis, organogenesis, the inflammatory reaction process, and cancer invasion and metastasis. Three $\mathrm{G}$ proteins of the Rho family-Rho, Cdc42, and Rac-are involved in the control of actin polymerization, ${ }^{1}$ and the genes of Wiskott-Aldrichsyndrome-related protein (WASP) and actin-related proteins (Arps) 2 and 3 have recently been demonstrated in the downstream of the genes of three $G$ proteins. ${ }^{2,3}$ Arp2/3 complex has been identified as binding to profilin, it consists of seven subunits, including Arp2 and Arp3. ${ }^{4}$ The Arp2/3 complex acts as a nucleus for actin polymerization and directly regulates the polymerization reaction by interacting with WASP family proteins. ${ }^{5,6}$ Although many studies have demonstrated the intracellular locali-

Correspondence: K Mukai, MD, Department of Pathology, Tokyo Medical University, Shinjuku 6-1-1, Shinjuku-ku, Tokyo 1608402, Japan.

E-mail: kmukai@tokyo-med.ac.jp

Received 7 July 2003; revised 26 November 2003; accepted 8 December 2003; published online 27 February 2004 zation of the Arp2/3 complex, the types of cells and/ or tissues that express it in vivo and how it works are unclear.

Invasion and metastasis begin with the movement of cancer cells from the primary focus in cancer tissue, and actin polymerization is necessary for this movement to occur. However, other factors such as cell adhesion and matrix degradation are also involved in the generation of cell movement. To understand the biological significance of the formation of Arp2/3 complex, we investigated the expression of Arp2 and Arp3 in the process of colorectal carcinogenesis and the relation between their expression and cancer invasion by immunohistochemically investigating the expression of Arp2 and Arp3 in colorectal neoplastic lesions in various stages of carcinogenesis.

\section{Materials and methods}

Patients and Tumor Specimens

We analyzed specimens of colorectal neoplasms from 175 Japanese patients, 159 of whom had 
undergone surgical resection and 16 of whom had done endoscopic resection at the Tokyo Medical University Hospital. Of the 175 cases, 169 had been used in our previous study. ${ }^{7}$ Blocks of formalinfixed, paraffin-embedded tissue of colorectal neoplasms were retrieved from the Surgical Pathology Division, and serial sections of each block were cut. One section was stained with hematoxylin and eosin (H \& E) for confirmation of the histopathological diagnosis by three pathologists. The histological diagnosis and depth of invasion were determined according to the Japanese classification of colorectal carcinoma. ${ }^{8}$ Briefly, the adenomas were classified into three grades of atypia according to their degree of cytological and architectural atypia: mild, moderate, or severe. When carcinoma cells were limited to the mucosa, the term 'intramucosal carcinoma' was used. Intramucosal carcinoma included carcinoma in adenoma and carcinoma without an adenomatous component, or de novo cancer. The term 'invasive carcinoma' was restricted to cancer that had invaded the submucosa or beyond.

\section{Immunohistochemical Staining of Arp2, Arp3, CD10, and p53}

One or two representative blocks from each tumor were selected for immunohistochemical analysis of Arp2 and Arp3. Serial 4- $\mu$ m-thick sections were cut from each paraffin block, and the sections were routinely deparaffinized with xylene, rehydrated with a series of ethanol washes, and then immersed in $0.3 \%$ hydrogen peroxide in absolute methanol for 15 min to block endogenous peroxidase activity. Nonenzymatic antigen retrieval was performed by autoclave heating in $0.01 \mathrm{M}$ sodium citrate buffer (pH 6.0) for $5 \mathrm{~min}$. After cooling, the sections were incubated with $10 \%$ normal swine serum in phosphate-buffered saline for $10 \mathrm{~min}$, and a biotinblocking system (DAKO Japan, Kyoto, Japan) was used to block endogenous biotin. The sections were then incubated with an anti-Arp2 goat monoclonal antibody (K-15, Santa Cruz Biotechnology, Santa Cruz, CA, USA) diluted to 1:1000 or an anti-Arp3 polyclonal antibody. The anti-Arp3 polyclonal antibody was generated by immunizing rabbits with the synthetic peptide CKVFMQEFKEGRRASHTAPQVLFSHRE, which corresponds to amino acids 178-204 of Arp3, and is superior to the commercially available monoclonal antibody against Arp3 (G-15, Santa Cruz Biotechnology), as it yielded higher signal intensity and lower background staining of colon samples. Therefore, the polyclonal antibody diluted to 1:5000 was selected for use in the study. The sections of colon cancer tissue, which Arp2 and Arp3 were confirmed to be expressed by immunoblot analysis, were used for the positive control of immunostaining of Arp2 and Arp3. For the negative control, the primary antibody was substituted by normal rabbit serum. Smooth muscle cells of small blood vessels were used as a built-innegative control in each section. CD10 and p53 were immunostained with an anti-CD10 mouse monoclonal antibody (56C6, Novocastra, Newcastle-uponTyne, UK) diluted to 1:100 and an anti-p53 mouse monoclonal antibody (DO-7, DAKO Japan) diluted to $1: 200$.

An LSAB kit (DAKO Japan) was used as the detection system. After incubating the sections with biotin-labeled secondary antibodies and horseradish peroxidase-labeled streptavidin, the color reaction was developed in $0.02 \% 3^{\prime}, 3^{\prime}$-diaminobenzidine hydrochloride and $0.02 \% \mathrm{H}_{2} \mathrm{O}_{2}$ in Tris buffer $(\mathrm{pH}$ 8.0). Hematoxylin was used for counterstaining.

\section{Evaluation of Immunostaining}

Arp2 and Arp3 expression was evaluated separately in the stromal and tumor cells. When neoplastic tubules or glands were surrounded by stromal cells expressing Arp2 and/or Arp3, expression by the stromal cells was judged to be positive. If more than $10 \%$ of the tumor cells expressed Arp2 and/or Arp3, expression by the tumor cells was judged to be positive. Three observers independently judged the results of immunostaining. Interobserver discordance was detected in a few cases. A consensus for these cases was reached after discussion using a multihead teaching microscope.

Expression of CD10 by the stromal cells was evaluated in the same manner as expression of Arp2 and Arp3. The tumor cells were judged to be p53positive when more than $10 \%$ of the nuclei clearly stained.

\section{Statistical Analysis}

Correlations between the clinicopathological features of the patients, and Arp2 and Arp3 expression were analyzed by the $\chi^{2}$ test. A $P$-value of $<0.05$ was considered indicative of statistical significance. Statistical data were analyzed with the SAS statistical package (StatView 5.0, SAS Institute Inc., Cary, NC, USA).

\section{Results}

\section{Distribution of Arp2 and Arp3}

The distribution of Arp2 in colorectal tissue coincided with that of Arp3, and identical expression of Arp2 and Arp3 (Arp2\&3) was observed in lymphocytes, neutrophils, macrophages, and vascular endothelial cells (Figure 1). No expression of Arp2\&3 was detected in the epithelial cells or stromal cells of normal mucosa, but expression of Arp2\&3 was detected in the stromal cells adjacent to the neoplastic ducts of adenomas and carcinomas, and in the tumor cells themselves (Figures 2 and 3). The distribution of Arp2 and Arp3 in the stromal cells 

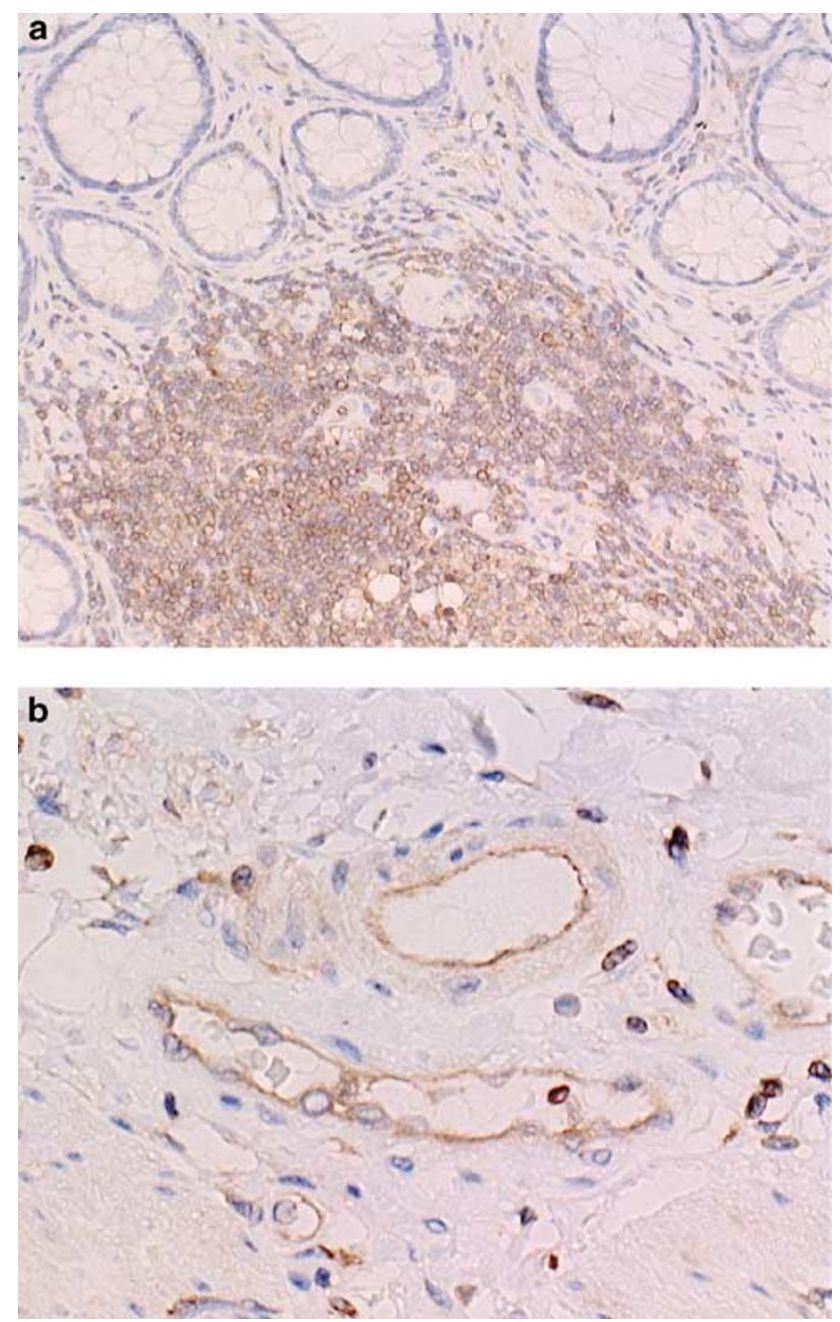

Figure 1 Expression of Arp2 in normal colonic mucosa. (a) Arp2 is expressed by lymphocytes forming lymph follicles and infiltrating the proper mucosal layer. No expression of Arp2 was detected in normal epithelial cells and stromal cells. (Immunohistochemistry of Arp2; original magnification $\times 200$ ) (b) Arp2 is expressed in the vascular endothelial cells and inflammatory cells. (Immunohistochemistry of Arp2; original magnification $\times 400)$.

and neoplastic cells was identical. Among the 175 colorectal tumors, the stromal cells were positive for Arp2\&3 in 88 (50.3\%), the tumor cells were positive for Arp2\&3 in $36(20.1 \%)$, and both the stromal and tumor cells were positive for Arp2\&3 in 27 (15.4\%). Strong expression of Arp2\&3 by the stromal cells was noted at the invasive front of the cancer tissue (Figure 4).

\section{Frequency of Expression of Arp2\&3 in Stromal Cells During Progression of Colorectal Neoplasms}

Arp2\&3 were expressed by the stromal cells of three $(5.5 \%)$ of the 55 adenomas with mild-to-moderate atypia and in two $(11.8 \%)$ of the 17 adenomas with severe atypia. They were positive in $16(53.3 \%)$ of the 30 intramucosal carcinomas and in 67 (91.8\%)

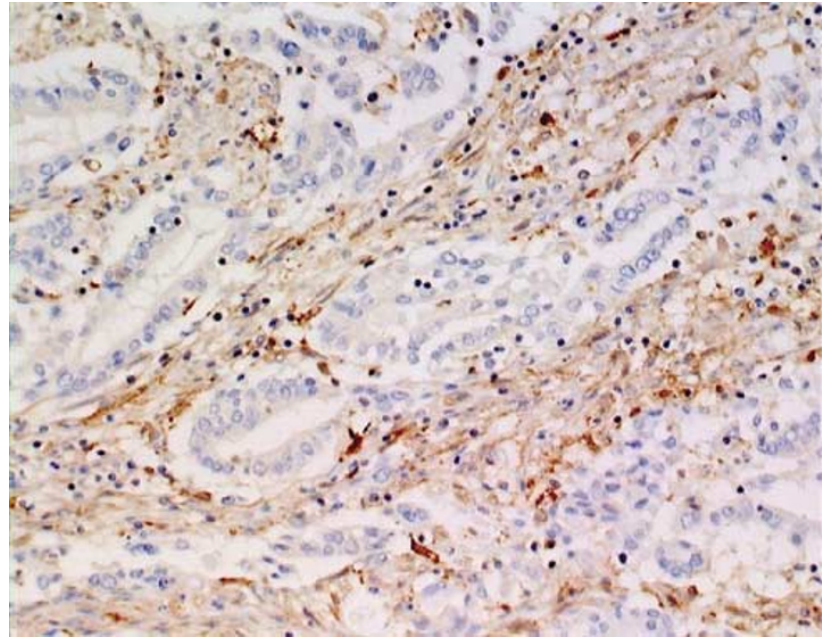

Figure 2 Expression of Arp2 by the stromal cells in the invasive portion of colorectal carcinoma. More than $10 \%$ of the stromal cells within the invasive portion of colorectal carcinoma expressed Arp2. (Immunohistochemistry of Arp2; original magnification $\times 300$ ).

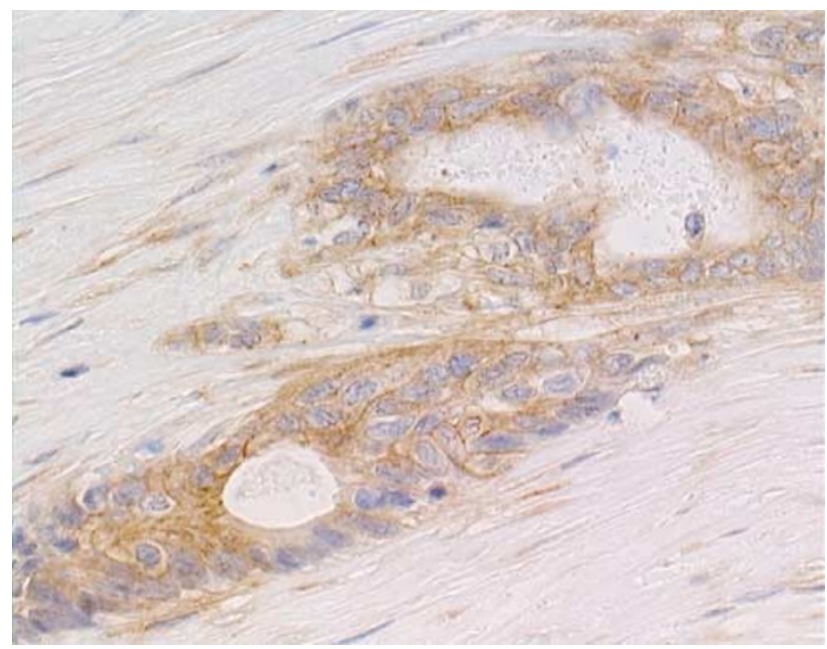

Figure 3 Expression of Arp2 by tumor cells. Arp2 is expressed in the invasive cancer cells. (Immunohistochemistry of Arp2; original magnification $\times 400$ ).

of the 73 invasive carcinomas. The frequency of Arp2\&3 expression was higher in carcinoma tissue than in adenoma tissue $(P<0.0001)$, and significantly higher frequency of Arp2\&3 expression was observed in the stromal cells of invasive carcinomas than of noninvasive carcinomas and adenomas $(P<0.0001)$ (Table 1).

\section{Frequency of Expression of Arp2\&3 in Tumor Cells During Progression of Colorectal Neoplasms}

Arp2\&3 expression by the tumor cells was observed in one $(1.8 \%)$. of the 55 adenomas with mild-tomoderate atypia and in four $(23.5 \%)$ of the 17 adenomas with severe atypia. Arp2\&3 expression was positive in the tumor cells in seven $(23.3 \%)$ 
of the 30 intramucosal carcinomas and $24(32.9 \%)$ of the 73 invasive carcinomas (Table 2). The frequency of Arp2\&3 expression was higher in the adenomas with severe atypia and carcinomas than in the adenomas with mild-to-moderate atypia $(P<0.0001)$.

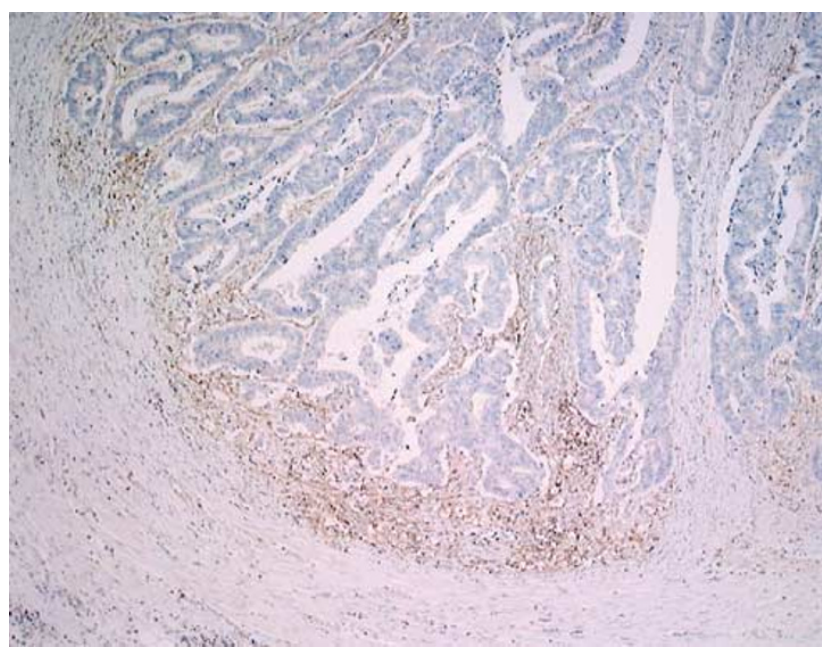

Figure 4 Strong expression of Arp2 at the invasive cancer front. Stromal cells positive for Arp2 were detected at the invasive front. (Immunohistochemistry of Arp2; original magnification $\times 100$ ).

Table 1 Expression of Arp2\&3 by stromal cells and progression of colorectal tumors

\begin{tabular}{|c|c|c|c|}
\hline & \multirow[t]{2}{*}{ No. of cases } & \multicolumn{2}{|c|}{$\begin{array}{c}\text { Arp } 2 \& 3 \\
\text { Stromal cells }\end{array}$} \\
\hline & & $\mathrm{n}$ & $\%$ \\
\hline \multicolumn{4}{|l|}{ Adenoma } \\
\hline Mild-moderate & 55 & 3 & 5.5 \\
\hline Severe & 17 & 2 & 11.8 \\
\hline Intramucosal carcinoma & 30 & 16 & 53.33 \\
\hline Invasive carcinoma & 73 & 67 & 91.8 \\
\hline Total & 175 & 88 & 50.3 \\
\hline
\end{tabular}

${ }^{\star} P<0.0001$.

Table 2 Expression of Arp2\&3 by tumor cells and progression of colorectal tumors

\begin{tabular}{|c|c|c|c|}
\hline & \multirow[t]{2}{*}{ No. of cases } & \multicolumn{2}{|c|}{$\begin{array}{c}\text { Arp2\&3 } \\
\text { Tumor cells }\end{array}$} \\
\hline & & $\mathrm{n}$ & $\%$ \\
\hline \multicolumn{4}{|l|}{$\Lambda$ denoma } \\
\hline Mild-moderate & 55 & 1 & 1.8 \\
\hline Severe & 17 & 4 & 23.57 \\
\hline Intramucosal carcinoma & 30 & 7 & 23.3 \\
\hline Invasive carcinoma & 73 & 24 & 32.9 \\
\hline Total & 175 & 36 & 20.6 \\
\hline
\end{tabular}

${ }^{\star} P<0.0001$

\section{Correlation between Arp2\&3 Expression and Depth of Invasion by Colorectal Cancer}

Table 3 shows the frequency of Arp2\&3 expression by the stromal cells of 103 colorectal cancers according to the depth of invasion. Arp2\&3 expression in stromal cells was significantly higher in invasive carcinoma, ranging from 86.7 to $100 \%$, than in intramucosal carcinoma $(P<0.0001)$. The frequency of Arp2\&3 expression by the cancer cells tended to increase with the depth of invasion of colorectal cancer (Table 4). It was positive in 11 of 43 $(25.6 \%)$ invasive cancers limited to the submucosal layer, five of $15(33.3 \%)$ cancers that had invaded the proper muscle layer, and eight of 15 (53.3\%) cancers that had invaded beyond the proper muscular layer, but the correlation was not statistically significant.

\section{Correlation between Expression of CD10 and Arp2\&3 by Stromal Cells}

CD10 has been shown to be expressed by tumorinduced stromal cells. ${ }^{7}$ The stromal cells in 86 $(49.1 \%)$ of 175 tumors were positive for CD10. Stromal expression of Arp2\&3 was observed in 61

Table 3 Correlation between Arp2\&3 expression by stromal cells and depth of invasion by colorectal cancer

\begin{tabular}{|c|c|c|c|}
\hline \multirow[t]{2}{*}{ Depth } & \multirow[t]{2}{*}{ No. of cases } & \multicolumn{2}{|c|}{$\begin{array}{c}\text { Arp2\&3 } \\
\text { Stromal cells }\end{array}$} \\
\hline & & $\mathrm{n}$ & $\%$ \\
\hline $\mathrm{m}$ & 30 & 16 & 53.3 \\
\hline $\mathrm{sm}$ & 43 & 39 & 90.17 \\
\hline $\mathrm{mp}$ & 15 & 15 & 100 \\
\hline ss & 15 & 13 & 86.7 \\
\hline Total & 103 & 83 & 80.6 \\
\hline
\end{tabular}

m: mucosal layer; sm: submucosal layer; mp: proprial muscular layer: ss: subserosal layer.

${ }^{*} P<0.0001$.

Table 4 Correlation between Arp2\&3 expression by cancer cells and depth of invasion by colorectal cancer

\begin{tabular}{lcrc}
\hline Depth & No. of cases & \multicolumn{2}{c}{$\begin{array}{c}\text { Arp2\&3 } \\
\text { Cancer cells }\end{array}$} \\
\cline { 3 - 4 } & & $\mathrm{n}$ & $\%$ \\
\hline $\mathrm{m}$ & 30 & 7 & 23.3 \\
$\mathrm{sm}$ & 43 & 11 & 25.6 \\
$\mathrm{mp}$ & 15 & 5 & 33.3 \\
$\mathrm{ss}$ & 15 & 8 & 53.3 \\
Total & 103 & 31 & 30.1 \\
\hline
\end{tabular}

m: mucosal layer; sm: submucosal layer; mp: proprial muscular layer; ss: subserosal layer. 
$(70.9 \%)$ of the 86 CD10-positive tumors, and there was a significant correlation between CD10 and Arp2\&3 expressions by the stromal cells (Table 5). As shown in Figure 5, the distribution of CD10 and Arp2 was nearly the same.

\section{Correlation between Expression of p53 and Arp2\&3 by Stromal Cells}

Accumulation of p53 in the nuclei of tumor cells was observed in $84(48.0 \%)$. of the 175 tumors. Stromal expression of Arp2\&3 was seen in 60 $(71.4 \%)$ of the 84 p53-positive tumors, and there was a significant correlation between the occurrence of p53 in the nuclei and Arp2\&3 expression (Table 6).

\section{Discussion}

Attempts have been made to elucidate intracellular signaling during cell movement, and direct involvement of the Arp2/3 complex has been demonstrated when actin filaments polymerize rapidly after exposure to various stimuli. Many reports have shown intracellular localization of the Arp2/3 complex in normal tissues, ${ }^{9-12}$ but there have been no reports on its distribution in cancer tissue. We detected identical expression of Arp2 and Arp3 by the neoplastic cells and the stromal cells of colorectal neoplasms. Since the distribution of Arp2 was the same as that of Arp3 in tumorous colorectal tissue, we concluded that the identical expression of Arp2 and Arp3 indicates the formation of Arp2/3 complex.

Arp2\&3 were not expressed in the epithelium or stromal cells of normal colorectal mucosa, but their expression was detected in macrophages, lymphocytes, and endothelial cells. As these cells are thought to function while migrating in tissues, cells that express Arp2\&3 may have greater ability to move freely than cells that do not. Similarly, the expression of Arp2\&3 by cancer and stromal cells partly explains their ability to migrate actively.

We previously reported that CD10 is expressed by stromal cells adjacent to neoplastic glands in color-

Table 5 Correlation between expression of Arp2\&3 and CD10 by stromal cells

\begin{tabular}{|c|c|c|c|c|c|}
\hline & \multirow[t]{3}{*}{ Total } & \multicolumn{4}{|c|}{ Arp2\&3 } \\
\hline & & \multicolumn{2}{|c|}{ Positive } & \multicolumn{2}{|c|}{ Negative } \\
\hline & & $\mathrm{n}$ & $\%$ & $\mathrm{n}$ & $\%$ \\
\hline \multicolumn{6}{|l|}{ CD10 } \\
\hline Positive & 86 & 61 & 70.9 & 25 & $29.1]$ \\
\hline Negative & 89 & 36 & 40.4 & 53 & $59.6]$ \\
\hline
\end{tabular}

${ }^{\star} P<0.0001$. ectal cancer, and that CD10 is a marker for stromal cells that have been activated by tumor cells. ${ }^{7}$ The fact that the expression of Arp2\&3 was correlated with that of CD10 and the distribution of the cells
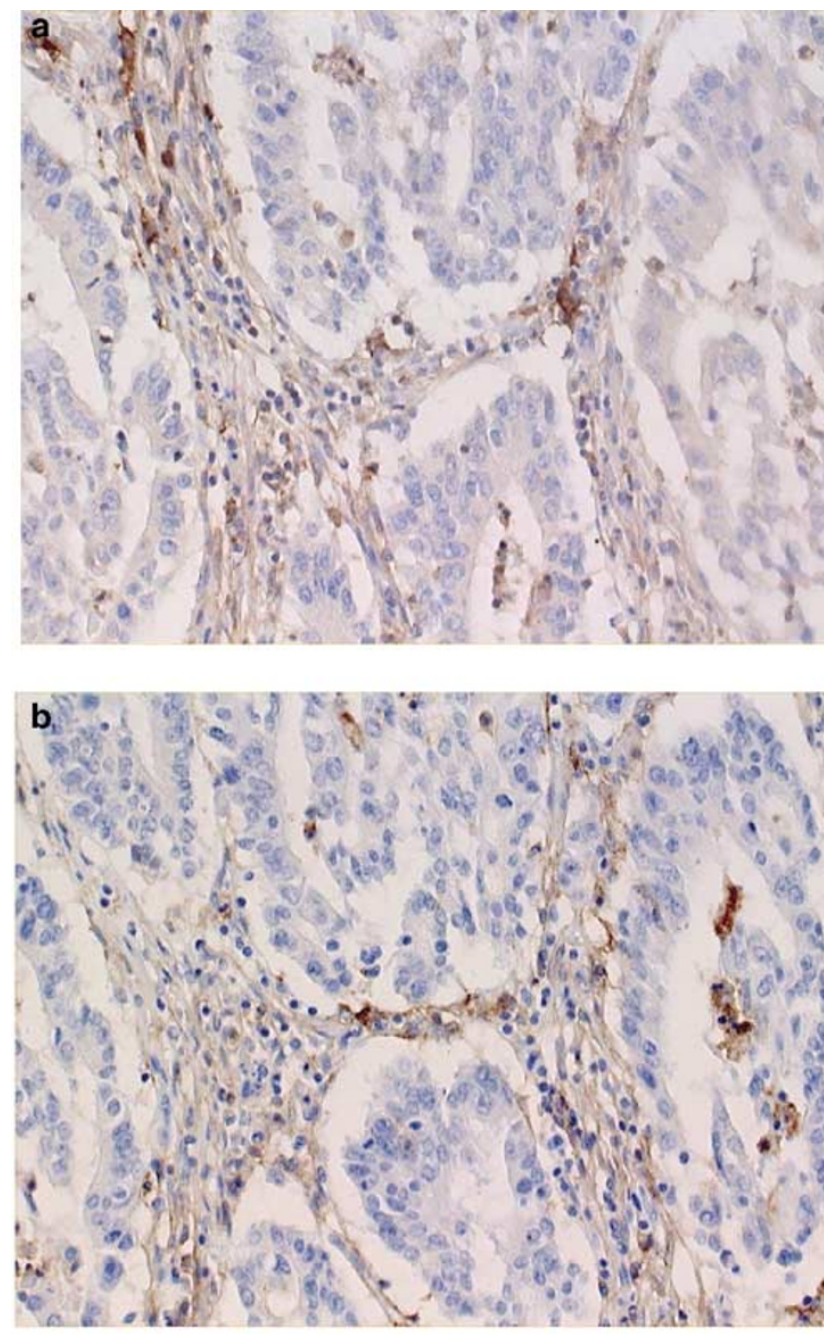

Figure 5 Distribution of Arp2- and CD10-positive stromal cells. Arp2 (a) and CD10 (b) in serial sections of colorectal carcinoma. The distribution of Arp2-positive stromal cells corresponded to that of CD10-positive stromal cells. (Immunohistochemistry of Arp2; original magnification $\times 300$ ).

Table 6 Correlation between stromal expression of Arp 2\&3 and nuclear accumulation of p53 protein

\begin{tabular}{|c|c|c|c|c|c|}
\hline & \multirow[t]{3}{*}{ Total } & \multicolumn{4}{|c|}{ Arp $2 \& 3$} \\
\hline & & \multicolumn{2}{|c|}{ Positive } & \multicolumn{2}{|c|}{ Negative } \\
\hline & & $\mathrm{n}$ & $\%$ & $\mathrm{n}$ & $\%$ \\
\hline \multicolumn{6}{|l|}{ p53 } \\
\hline Positive & 84 & 60 & 71.4 & 24 & $28.6]$ \\
\hline Negative & 91 & 37 & 40.7 & 54 & 59.3 \\
\hline
\end{tabular}

${ }^{*} P<0.0001$. 
expressing these two markers matched suggests that Arp2\&3 is probably expressed by stromal cells that have been induced by tumor cells.

Arp2\&3-positive stromal cells were rarely seen in low-grade adenomas, but they tended to become more frequent with the morphological progression of colorectal tumor. Arp2\&3-positive stromal cells were seen in a high percentage of invasive carcinomas, and there was a significant difference in the frequency of Arp2\&3-positive stromal cells between noninvasive intramucosal lesions and invasive carcinomas. Their occurrence was also correlated with abnormal accumulation of p53 protein. The emergence of stromal cells that expressed Arp2\&3 appeared to be closely associated with the transformation of adenomas with severe atypia into carcinomas.

Analysis according to depth of invasion by colorectal cancer showed that tumor cells were more frequently positive for Arp2\&3 as the invasion increased, and Arp2\&3 expression by the cancer cells was more often seen at the invasive front of the cancer. These observations also pointed to the involvement of Arp2\&3 expression in cancer invasion following carcinogenesis.

Arp2\&3 were more strongly expressed by the stromal cells than by the cancer cells, and Arp2\&3 expression tended to be greater in the stromal cells at the invasive front of the cancer. These observations suggest that the stromal cells expressing Arp2\&3 move and grow in advance of the cancer cells to prepare an environment that facilitates cancer cells' invasion, and indeed myofibroblasts, which are considered cancer-induced stromal cells, have been shown to affect the adhesion and movement of cancer cells. ${ }^{13}$ Other studies have shown that patients whose cancer exhibits marked fibrosis have a poorer outcome than those who have cancer without significant fibrosis. ${ }^{14,15}$

The ability of cancer cells to invade is controlled by tumor-stromal interaction. Stromal cells have been reported to control cancer cell adhesion and movement, ${ }^{16-18}$ and stromal cells produce cytokines, including interleukin (IL)-1. ${ }^{19-21}$ Actin fiber formation mediated by the action of the Arp2/3 complex begins rapidly when cell migration is induced by cytokines. Activated fibroblasts also produce transforming growth factor- $\beta$, matrix metalloproteinase (MMP) 11, and hepatocyte growth factor (HGF), which are involved in cancer cell invasion. ${ }^{21-27} \mathrm{HGF}$, in particular, is known to be induced by cancer-cellderived IL-1, platelet-derived growth factor, basic fibroblast growth factor, epidermal growth factor, and prostaglandins, and to play a role as a mediator of tumor-stromal interaction in various types of malignancy. ${ }^{28,29}$

Many studies have reported overexpression of cMet or an HGF receptor by colorectal cancer. ${ }^{30-33}$ Increased cell movement induced by HGF requires activation of Rho protein, and Rac and Rho are involved in cell membrane ruffling during the cell movement caused by HGF. ${ }^{34}$ HGF controls the WASP family protein N-WASP, and is related to cell movement and invasion. ${ }^{35}$ HGF appears to activate the Arp2/3 complex and promote cell scattering. A model of invasion that used various cancer cell lines has indicated involvement of the Rho family in cancer invasion. ${ }^{36-38}$ Invasion presumably occurs by a similar system in vivo, and the Arp2/3 complex is thought to be controlled by tumor-stromal interaction and to be involved in cancer invasion.

The results of our study indicated that the Arp2/3 complex may be involved in the invasion of colorectal cancer. Further studies on the role of the Arp2/3 complex in tumor-stromal interaction are needed to develop effective cancer therapy by inhibiting cancer cell movement.

\section{Acknowledgements}

We thank Dr Hitoshi Ogawa for technical assistance with the immunohistochemical studies. This study was supported in part by Grants in Aid for Cancer Research and for the Second-Term Comprehensive Strategy for Cancer Control from the Ministry of Health, Labour, and Welfare.

\section{References}

1 Van Aelst L, D’Souza-Schorey C. Rho GTPases and signaling networks. Genes Dev 1997;11:2295-2322.

2 Takenawa T, Miki H. WASP and WAVE family proteins: key molecules for rapid rearrangement of cortical actin filaments and cell movement. J Cell Sci 2001;114:1801-1809.

3 Higgs HN, Pollard TD. Regulation of actin filament network formation through ARP2/3 complex: activation by a diverse array of proteins. Annu Rev Biochem 2001;70:649-676.

4 Machesky LM, Atkinson SJ, Ampe C, et al. Purification of a cortical complex containing two unconventional actins from Acanthamoeba by affinity chromatography on profilin-agarose. J Cell Biol 1994;127:107-115.

5 Rohatgi R, Ma L, Miki H, et al. The interaction between N-WASP and the Arp2/3 complex links Cdc42-dependent signals to actin assembly. Cell 1999;97:221-231.

6 Machesky LM, Mullins RD, Higgs HN, et al. Scar, a WASp-related protein, activates nucleation of actin filaments by the Arp2/3 complex. Proc Natl Acad Sci USA 1999;96:3739-3744.

7 Ogawa H, Iwaya K, Izumi M, et al. Expression of CD10 by stromal cells during colorectal tumor development. Hum Pathol 2002;33:806-811.

8 Japanese Society for the Colon and Rectum. Japanese Classification of Colorectal Carcinoma. Kanehara: Tokyo, 1997.

9 Moreau V, Madania A, Martin RP, et al. The Saccharomyces cerevisiae actin-related protein Arp2 is involved in the actin cytoskeleton. J Cell Biol 1996;134:117-132.

10 Winter D, Podtelejnikov AV, Mann M, et al. The complex containing actin-related proteins Arp2 and 
Arp3 is required for the motility and integrity of yeast actin patches. Curr Biol 1997;7:519-529.

11 Welch MD, DePace AH, Verma S, et al. The human Arp2/3 complex is composed of evolutionarily conserved subunits and is localized to cellular regions of dynamic actin filament assembly. J Cell Biol 1997;138:375-384.

12 Mullins RD, Stafford WF, Pollard TD. Structure, subunit topology, and actin-binding activity of the Arp2/3 complex from Acanthamoeba. J Cell Biol 1997;136:331-343.

13 Martin M, Pujuguet P, Martin F. Role of stromal myofibroblasts infiltrating colon cancer in tumor invasion. Pathol Res Pract 1996;192:712-717.

14 Halvorsen TB, Seim E. Association between invasiveness, inflammatory reaction, desmoplasia and survival in colorectal cancer. J Clin Pathol 1989;42:162-166.

15 Ponz de Leon M, Sant M, Micheli A, et al. Clinical and pathologic prognostic indicators in colorectal cancer. A population-based study. Cancer 1992;69:626-635.

16 Tran NL, Nagle RB, Cress AE, et al. N-Cadherin expression in human prostate carcinoma cell lines. An epithelial-mesenchymal transformation mediating adhesion with stromal cells. Am J Pathol 1999;155:787-798.

17 Park JE, Lenter MC, Zimmermann RN, et al. Fibroblast activation protein, a dual specificity serine protease expressed in reactive human tumor stromal fibroblasts. J Biol Chem 1999;274:36505-36512.

18 Sternlicht MD, Lochter A, Sympson CJ, et al. The stromal proteinase MMP3/stromelysin-1 promotes mammary carcinogenesis. Cell 1999;98:137-146.

19 Gohji K, Nakajima M, Fabra A, et al. Regulation of gelatinase production in metastatic renal cell carcinoma by organ-specific fibroblasts. Jpn J Cancer Res 1994;85:152-160.

20 Orphanos V, Andonopoulos AP, Kourakli A, et al. Cytokine gene expression in the marrow stromal cells of patients with giant cell arteritis. Clin Exp Rheumatol 1998;16:683-688.

21 Bergqvist A, Nejaty H, Froysa B, et al. Production of interleukins 1beta, 6 and 8 and tumor necrosis factor alpha in separated and cultured endometrial and endometriotic stromal and epithelial cells. Gynecol Obstet Invest 2000;50:1-6.

22 Muller D, Wolf C, Abecassis J, et al. Increased stromelysin 3 gene expression is associated with increased local invasiveness in head and neck squamous cell carcinomas. Cancer Res 1993;53:165-169.

23 Porte H, Chastre E, Prevot S, et al. Neoplastic progression of human colorectal cancer is associated with overexpression of the stromelysin-3 and BM-40/ SPARC genes. Int J Cancer 1995;64:70-75.

24 Inoue $\mathrm{T}$, Chung YS, Yashiro $\mathrm{M}$, et al. Transforming growth factor-beta and hepatocyte growth factor produced by gastric fibroblasts stimulate the invasiveness of scirrhous gastric cancer cells. Jpn J Cancer Res 1997;88:152-159.

25 Shimao Y, Nabeshima K, Inoue $\mathrm{T}$, et al. Role of fibroblasts in $\mathrm{HGF} / \mathrm{SF}$-induced cohort migration of human colorectal carcinoma cells: fibroblasts stimulate migration associated with increased fibronectin production via upregulated TGF-beta1. Int J Cancer 1999;82:449-458.

26 Boulay A, Masson R, Chenard MP, et al. High cancer cell death in syngeneic tumors developed in host mice deficient for the stromelysin-3 matrix metalloproteinase. Cancer Res 2001;61:2189-2193.

27 Delany AM, Canalis E. The metastasis-associated metalloproteinase stromelysin-3 is induced by transforming growth factor-beta in osteoblasts and fibroblasts. Endocrinology 2001;142:1561-1566.

28 Matsumoto K, Date K, Shimura H, et al. Acquisition of invasive phenotype in gallbladder cancer cells via mutual interaction of stromal fibroblasts and cancer cells as mediated by hepatocyte growth factor. Jpn J Cancer Res 1996;87:702-710.

29 Nakamura T, Matsumoto K, Kiritoshi A, et al. Induction of hepatocyte growth factor in fibroblasts by tumor-derived factors affects invasive growth of tumor cells: in vitro analysis of tumor-stromal interactions. Cancer Res 1997;57:3305-3313.

30 Liu C, Park M, Tsao MS. Overexpression of c-met proto-oncogene but not epidermal growth factor receptor or c-erbB-2 in primary human colorectal carcinomas. Oncogene 1992;7:181-185.

31 Di Renzo MF, Olivero M, Giacomini A, et al. Overexpression and amplification of the met/HGF receptor gene during the progression of colorectal cancer. Clin Cancer Res 1995;1:147-154.

32 Wielenga VJ, van der Voort $\mathrm{R}$, Taher TE, et al. Expression of c-Met and heparan-sulfate proteoglycan forms of CD44 in colorectal cancer. Am J Pathol 2000;157:1563-1573.

33 Otte JM, Schmitz F, Kiehne K, et al. Functional expression of HGF and its receptor in human colorectal cancer. Digestion 2000;61:237-246.

34 Nishiyama T, Sasaki T, Takaishi K, et al. rac p21 is involved in insulin-induced membrane ruffling and rho p21 is involved in hepatocyte growth factor- and 12-O-tetradecanoylphorbol-13-acetate (TPA)-induced membrane ruffling in $\mathrm{KB}$ cells. Mol Cell Biol 1994;14:2447-2456.

35 Yamaguchi H, Miki H, Takenawa T. Neural WiskottAldrich syndrome protein is involved in hepatocyte growth factor-induced migration, invasion, and tubulogenesis of epithelial cells. Cancer Res 2002;62: 2503-2509.

36 Yoshioka K, Imamura F, Shinkai K, et al. Participation of rhop21 in serum-dependent invasion by rat ascites hepatoma cells. FEBS Lett 1995;372:25-28.

37 Stam JC, Michiels F, van der Kammen RA, et al. Invasion of T-lymphoma cells: cooperation between Rho family GTPases and lysophospholipid receptor signaling. EMBO J 1998;17:4066-4074.

38 Collisson EA, Carranza DC, Chen IY, et al. Isoprenylation is necessary for the full invasive potential of RhoA overexpression in human melanoma cells. J Invest Dermatol 2002;119:1172-1176. 